\title{
A comparison of the influence of breast-feeding and bottle-feeding on the fatty acid composition of the erythrocytes
}

\author{
BY T. A. B. SANDERS AND D. J. NAISMITH \\ Department of Nutrition, Queen Elizabeth College, London $\mathrm{W}^{7} \mathrm{7AH}$ \\ (Received 30 November 1978 - Accepted 18 December 1978)
}

\begin{abstract}
The proportion of long-chain polyunsaturated derivatives of linoleic and linolenic acids in the erythrocyte lipids of infants fed a cow's milk formula was lower than in breast-fed infants. Although the formula provided only $0.55 \%$ of the total energy as linoleic acid, essential fatty acid deficiency was not detected; the triene: tetraene ratio was 0.09 .
\end{abstract}

Essential fatty acid (EFA) deficiency can be recognized by changes of the proportions

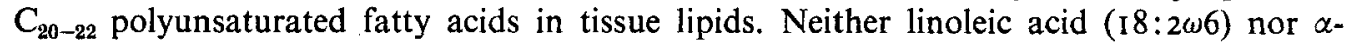
linolenic acid ( $18: 3 \omega 3)$ can be synthesized by mammalian cells. Both can, however, undergo chain elongation and desaturation in animal tissues to give rise to two separate series of $\mathrm{C}_{20-22}$ polyunsaturated fatty acids, the $\omega 6$ and $\omega_{3}$ series, derived from linoleic and $\alpha$-linolenic acids respectively; no interconversion occurs between the two series (Holman, 1970).

When the diet is lacking in linoleic and $\alpha$-linolenic acids, there is a fall in the proportions of their long-chain polyunsaturated (LCP) derivatives in the tissue lipids accompanied by a compensatory rise in the proportion of an eicosatrienoic acid $(20: 3 \omega 9)$ that can be readily synthesized from carbohydrate. Holman (1960) proposed that a ratio of eicosatrienoic acid:arachidonic acid $(20: 4 \omega 6)$, the so-called triene : tetraene ratio, in excess of 0.4 may be taken to indicate linoleic acid (essential fatty acid) deficiency.

Most infants in the United Kingdom are fed modified cow's milk formulas (Department of Health and Social Security, 1974). Soderhjelm et al. (1970) have alleged that cow's milk formulas containing butterfat only fail to provide the infant with the minimum requirement for linoleic acid. This opinion, however, has recently been challenged. Naismith et al. (1978) studied twenty normal full-term infants who were fed solely a modified cow's milk formula (Glaxo Complete Formula) for the first 14 weeks of life. Their rates of growth in length and in weight were identical with those of twenty wholly breast-fed infants, the normal decline in energy intake in relation to body-weight was noted, and clinical signs of linoleic acid deficiency were not observed. Analysis of the total plasma lipids for fatty acids showed that, although the triene:tetraene ratio did not approach the critical value of 0.4 , the proportion of arachidonic acid was approximately half that found in breast-fed infants. The LCP derivatives of $\alpha$-linolenic acid were not estimated.

The analysis of plasma, although most convenient, may give an exaggerated impression of the deficiency state. The triene:tetraene ratio in the plasma lipids of infants has been found to rise above 0.4 within a few days of initiating parenteral feeding with fat-free solutions, whereas the ratio in tissue lipids was little affected even after several weeks (Paulsrud et al. 1972). The lipids of the erythrocytes might be thought to give a better reflection of tissue fatty acid status. Their rate of turnover, although slower than in plasma, is higher than in most tissues (Farquar \& Ahrens, 1963; Cooper, 1970); they are almost entirely associated with cell membranes (Dodge et al. 1963) and contain a high proportion of LCP (Dodge \& Phillips, 1967). 
Table I. $\omega 6$ and $\omega_{3}$ polyunsaturated fatty acids provided by the cow's milk formula and by breast-milk

\begin{tabular}{|c|c|c|c|c|c|}
\hline & \multicolumn{3}{|c|}{ Wt of fatty acid methyl esters detected $(\%)$} & \multirow{2}{*}{\multicolumn{2}{|c|}{$\begin{array}{l}\text { Calculated contribution to } \\
\text { total dietary energy }(\%)\end{array}$}} \\
\hline & \multirow[b]{2}{*}{ Milk formula } & \multicolumn{2}{|c|}{ Breast-milk (four samples) } & & \\
\hline & & Mean & SE & Milk formula & Breast-milk \\
\hline $18: 2 \omega 6$ & $1 \cdot 60$ & 6.90 & $0.8 \mathrm{I}$ & 0.553 & 3.540 \\
\hline $18: 3 \omega_{3}$ & 0.70 & 0.80 & 0.05 & 0.242 & 0.410 \\
\hline $20: 2 \omega 6$ & nd & 0.18 & 0.03 & - & 0.092 \\
\hline $20: 3 \omega 6$ & 0.06 & 0.23 & 0.02 & 0.021 & 0.118 \\
\hline $20: 4 \omega 6+20: 3 \omega 3$ & $0.10^{*}$ & $0.54 \dagger$ & 0.01 & 0.035 & 0.277 \\
\hline $20: 4 \omega_{3}$ & 0.06 & 0.09 & 0.02 & 0.021 & 0.046 \\
\hline $20: 5 \omega_{3}$ & 0.08 & 0.20 & 0.08 & 0.028 & 0.103 \\
\hline $22: 4 \omega 6$ & 0.01 & 0.08 & 0.03 & 0.004 & 0.041 \\
\hline $22: 5 \omega 6$ & 0.01 & 0.15 & 0.12 & 0.004 & 0.077 \\
\hline $22: 5 \omega_{3}$ & $0 . I I$ & 0.52 & 0.27 & 0.038 & 0.267 \\
\hline $22: 6 \omega 3$ & 0.02 & 0.59 & 0.23 & 0.007 & 0.303 \\
\hline
\end{tabular}

We decided, therefore, to examine the fatty acid composition of erythrocyte lipids in infants who participated in the study of Naismith et al. (1978).

\section{METHODS}

Heel-prick blood samples were obtained from I4-week-old infants who had been fed from birth a modified cow's milk formula, or had been breast-fed. Total erythrocyte lipids were analysed for fatty acids by the method of Sanders et al. (1978) using gas-liquid chromatography (GLC). Mid-stream milk samples, provided by the mothers of the breast-fed infants after 3 months of lactation, were also analysed to determine fatty acid composition.

Fatty acid analyses were made on the same batch of infant milk formula that was used in the study. Methyl esters were prepared from a total lipid extract and purified by thinlayer chromatography (TLC) (Sanders et al. 1978). The purified esters were then separated by argentation TLC (Morris, I966) according to extent of unsaturation and configuration of double bonds using toluene-hexane $(80: 30, \mathrm{v} / \mathrm{v})$ as the developing solvent. After elution from the TLC absorbent, the various fractions were analysed by GLC with a known amount of internal standard (Dudley \& Anderson, 1975). The fraction identified as containing the cis-cis dienes was analysed by GLC-mass spectroscopy, and two positional isomers of linoleic acid, which were separated at $160^{\circ}$ on a $3 \mathrm{~m} \times 6.4 \mathrm{~mm}$ o.d. glass column packed with $80 \mathrm{~g}$ Silar $10 \mathrm{C} / \mathrm{kg}$ Chromosorb W (100-1 20 mesh) AW/DMCS (Field Instruments Ltd, Twickenham, Middlesex), were identified. GLC-mass spectroscopy of trimethyl siloxy derivates (McCloskey, 1970) confirmed that the major isomer was $18: 2 \omega 6$.

The Fischer-Behrens test was used for the statistical evaluation of the results.

\section{RESULTS AND DISCUSSION}

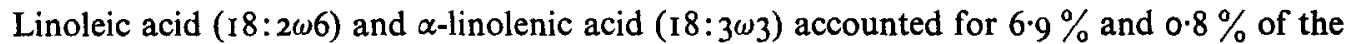
total fatty acids in the breast-milk samples, values similar to those reported for pooled samples of breast-milk obtained from five different areas of the United Kingdom (Department of Health and Social Security, 1977). In that survey, mean values reported for energy 
Table 2. The fatty acid composition of total erythrocyte lipids from I4-week-old infants who were either bottle-fed a cow's milk formula or breast-fed

(Mean values with their standard errors; results expressed as $\%$ total fatty acid methyl esters and dimethylacetals detected on a weight basis)

Methyl esters and dimethylacetals

(DMA)

$16: 0$ DMA
16:0
$18: 0$ DMA
$18: 0$
$18: 1$
$22: 0$
$24: 0$
$24: 1$
$18: 2$
$20: 2$
$20: 3 \omega 9$
$20: 3 \omega 6$
$20: 4 \omega 6$
$22: 4 \omega 6$
$22: 5 \omega 6$
$20: 5 \omega 3$
$22: 5 \omega 3$
$22: 6 \omega 3$
$20: 3 \omega 9: 20: 4 \omega 6$
$22: 5 \omega 3: 22: 6 \omega 3$

\begin{tabular}{lc}
\multicolumn{2}{c}{ Bottle-fed $(n$ I2) } \\
Mean & SE \\
2.9 & 0.53 \\
$21 \cdot 2$ & 0.46 \\
2.9 & 0.18 \\
$16 \cdot 2^{* *}$ & 0.32 \\
$15.4^{* *}$ & 0.39 \\
2.3 & 0.10 \\
4.2 & 0.25 \\
5.1 & 0.29 \\
$4.3^{* *}$ & 0.33 \\
$0.2^{*}$ & 0.06 \\
$1 \cdot 1^{* *}$ & 0.04 \\
$1 \cdot 3^{*}$ & 0.10 \\
$12.0^{*}$ & 0.39 \\
$1.3^{* *}$ & 0.10 \\
$0.7^{*}$ & 0.16 \\
$1 \cdot 2^{*}$ & 0.12 \\
$2.6^{*}$ & 0.25 \\
$3.7^{* *}$ & 0.21 \\
$0.09^{* *}$ & 0.005 \\
$0.7^{* *}$ & 0.067 \\
&
\end{tabular}

\begin{tabular}{rc}
\multicolumn{2}{c}{ Breast-fed $(n$ 6) } \\
\hline Mean & SE \\
2.3 & 0.19 \\
2.4 & 0.49 \\
17.7 & 0.17 \\
12.8 & 0.15 \\
2.4 & 0.23 \\
4.6 & 0.25 \\
5.2 & 0.39 \\
6.0 & 0.51 \\
0.1 & 0.31 \\
0.2 & 0.02 \\
0.9 & 0.03 \\
13.7 & 0.10 \\
2.3 & 0.62 \\
0.5 & 0.30 \\
0.7 & 0.32 \\
1.8 & 0.17 \\
6.2 & 0.16 \\
0.01 & 0.41 \\
0.29 & 0.003 \\
9.9 & 0.028
\end{tabular}

Statistical significance of difference between mean values: $* P<0.05$, ${ }^{*} P<0.01$.

and fat content were $70 \mathrm{Kcal} / 100 \mathrm{ml}$ and $4.2 \mathrm{~g} / 100 \mathrm{ml}$. In the present study, the cow's milk formula was not analysed for energy and fat. Instead, values supplied by the manufacturer were used, $470 \mathrm{Kcal} / \mathrm{I} 00 \mathrm{~g}$ and $\mathrm{I} 9 \mathrm{~g}$ fat $/ 100 \mathrm{~g}$. These values were used to calculate the proportion of the dietary energy provided by EFA, a factor of 0.95 being applied to allow for the non-fatty acid components of fat (Table I).

Linoleic acid ( $18: 2 \omega 6)$ and its LCP derivatives provided $0.55 \%$ and $0.03 \%$ of the energy in the milk formula, compared with $3.54 \%$ and $0.61 \%$ in breast milk; linolenic acid $\left(18: 3 \omega_{3}\right)$ and its derivatives contributed $0.24 \%$ and $0.13 \%$ of the total energy of the milk formula compared with $0.41 \%$ and $0.72 \%$ in breast milk.

The fatty acid composition of the erythrocyte lipids of the bottle-fed infants was characteristic of a low intake of linoleic acid, but did not indicate essential fatty acid deficiency. The proportions of linoleic acid and its derivative $(20: 4 \omega 6)$ were lower, and those of $18: 1$, 20:2 and 20:3 $3^{\omega}$ were higher than in the breast-fed infants, but the triene:tetraene ratio was well below the critical value of 0.4 in all infants (Table 2). It is noteworthy that the mean value for the triene: tetraene ratio in the erythrocyte lipids (0.09) was less than half the value found in the plasma lipids (0.22) in the same infants (Naismith et al. 1978).

It is perhaps not surprising that we failed to find evidence of EFA deficiency in the bottlefed infants. In discussions of the EFA requirements of the young infant, the fact is invariably overlooked that Hansen and his colleagues (Hansen et al. 1963) were able to prevent or cure linoleic acid deficiency using a modified cow's milk formula. Although they estimated that linoleic acid accounted for $1 \cdot 3 \%$ of the energy in their formula, it is likely to have been an over-estimate (Cuthbertson, 1976). Strocchi \& Holman (1971) and Kiuru et al. (1974) have shown that $50-80 \%$ only of the total linoleic acid in butterfat is the 
biologically-active isomer I $8: 2 \omega 6$. In our analyses, I $8: 2 \omega 6$ was separated from other geometric and positional isomers.

Crawford et al. (1976) hold the opinion that the arachidonic acid (20:4w6) in breastmilk plays an important part in meeting the lipid requirements of the infant, especially with regard to brain growth. Arachidonic acid was found in appreciable amounts in the plasma and erythrocytes of the bottle-fed infants, despite its virtual absence from the milk formula. Olegard \& Svennerholm (1971) were unable to find significant differences in the proportion of arachidonic acid in plasma and erythrocyte phosphoglycerides of 3-month-old infants who had either been breast-fed, or bottle-fed a skimmed-milk formula fortified with vegetable fat. As vegetable fat is devoid of arachidonic acid and skimmed milk contains a trace amount only, this implies that linoleic acid is readily converted to arachidonic acid in the young infant.

The role of linolenic acid $\left(18: 3 \omega_{3}\right)$ in human nutrition has yet to be clarified. There is some evidence that linolenic acid is an essential fatty acid for the rat (Lamptey \& Walker, 1976). As the LCP derivative of linolenic acid, 22:6.13, is a major constituent of human brain lipids (Svennerholm, I968) and 20:5 $\omega_{3}$ is the precursor of prostaglandin $E_{3}$, the argument that linolenic acid should also be regarded as essential for man is a cogent one.

The addition of linolenic acid to diets low in linoleic acid has been shown to suppress the synthesis of eicosatrienoic acid $(20: 3 \omega 9)$, to stimulate growth and prevent the development of dermal symptoms in the rat (Mohrhauer \& Holman, 1963). Although no such observation has been made in man, it is possible that the amount of linolenic acid and its derivatives in the cow's milk formula used in the present investigation may have been sufficient to modulate the response to the low intake of linoleic acid.

The proportions of $20: 5 \omega_{3}$ and $22: 5 \omega_{3}$ were higher, and that of $22: 6 \omega_{3}$ was substantially lower in the erythrocyte lipids of the bottle-fed infants. This difference was emphasized when the ratio $22: 5 \omega_{3}: 22: 6 \omega_{3}$ was calculated (Table 2 ). The proportion of total $\omega_{3}$ LCP was not, however, different.

The relative accumulation of the pentaenes $20: 5 \omega_{3}$ and $22: 5 \omega_{3}$ suggests either that there was retroconversion of $22: 6 \omega_{3}$ (Schlenk et al. 1969) or, more likely, that the rate of $\Delta_{4}$ desaturation is slow in man. Indeed, Sprecher (1977) has shown the rate of $\Delta_{4}$ desaturation to be very slow in the rat.

Although the proportion of $22: 6 \omega_{3}$ was lower in the erythrocytes of the bottle-fed infants than in their breast-fed controls, even lower values have been reported in infants fed breast-milk particularly rich in linoleic acid (Sanders et al. 1978). Whether these variations are of importance remains to be determined, but they do not appear to affect the general health of the infants.

Our findings suggest that the minimum requirement of the young infant for linoleic acid is substantially less than I \% of the dietary energy (Holman et al. 1964), the value most widely quoted.

\section{REFERENCES}

Cooper, R. A. (1970). Seminars Haemat. 7, 296.

Crawford, M. A., Hall, B., Laurence, B. M. \& Munhambo, A. (1976). Curr. med. Res. Opinion 4, suppl. I, 33 .

Cuthbertson, W. F. J. (1976). Am. J. clin. Nutr. 29, 559.

Department of Health and Social Security (1974). Rep. Hlth soc. Subj. no. 9.

Department of Health and Social Security (1977). Rep. Hlth soc. Subj. no. I 2.

Dodge, J. T., Mitchell, C. \& Hanahan, D. J. (1963). Archs Biochem. Biophys. 1oo, I 19.

Dodge, J. T. \& Phillips, G. B. (1967). J. Lipid Res. 8, 667.

Dudley, P. A. \& Anderson, R. E. (1975). Lipids ro, 113.

Farquar, J. W. \& Ahrens, E. H. (1963). J. clin. Invest. 42, 675.

Hansen, A. E., Wiese, H. F., Boelsche, A. N., Haggard, M. E., Adam, D. J. D. \& Davis, H. (1963). Pediatrics, Springfield. 3r, I7I. 
Holman, R. T. (1960). J. Nutr. 70, 405.

Holman, R. T. (editor) (1970). In Progress in the Chemistry of Fats and other Lipids, vol. 9, pp. $275,607$. Oxford: Pergamon Press.

Holman, R. T., Caster, W. O. \& Wiese, H. F. (1964). Am. J. clin. Nutr. 14, 70.

Kiuru, K., Leppanen, R. \& Antila, M. (1974). Fette Seifen Anstrichmittel 76, 401.

Lamptey, M. S. \& Walker, B. L. (1976). J. Nutr. 106, 86.

McCloskey, J. A. (1970). In Topics in Lipid Chemistry, vol. I, p. 369. [F. D. Gunstone, editor]. London: Logos Press.

Mohrhauer, H. \& Holman, R. T. (1963). J. Nutr. 81, 67.

Morris, L. J. (1966). J. Lipid Res. 7, 717.

Naismith, D. J., Deeprose, S. P., Supramaniam, G. \& Williams, M. J. H. (1978). Archs Dis. Childh. 53, 845.

Olegard, R. \& Svennerholm, L. (1971). Acta paediat. scand. 60, 505.

Paulsrud, J. R., Pensler, L., Whitten, C. F., Stewart, S. \& Holman, R. T. (1972). Am. J. clin. Nutr. $25,897$.

Sanders, T. A. B., Ellis, F. R. \& Dickerson, J. W. T. (1978). Am. J. clin. Nutr. 31, 805.

Schlenk, H., Sand, D. \& Gellerman, J. L. (1969). Biochim. biophys. Acta r87, $20 \mathrm{I}$.

Soderhjelm, L., Wiese, H. F. \& Holman, R. T. (1970). In Progress in the Chemistry of Fats and Other Lipids. vol. 9, p. 555 [R. T. Holman, editor]. Oxford: Pergamon Press.

Sprecher, H. (1977). Polyunsaturated Fatty Acids. p. I [W. H. Kunau and R. T. Holman, editors]. Illinois: American Oil Chemists Society.

Strocchi, A. \& Holman, R. T. (197I). Olii miner. 48, 6I 7.

Svennerholm, L. (1968). J. Lipid Res. 9, 570. 